\title{
Interactive comment on "Impacts of Enhanced Weathering on biomass production for negative emission technologies and soil hydrology" by Wagner de Oliveira Garcia et al.
}

\author{
Daniel Ibarra (Referee) \\ dibarra@berkeley.edu \\ Received and published: 8 January 2020
}

This study assesses the impact of enhanced weathering on biomass production as applied for negative emissions and looks at the global scale impact on soil hydrology. The calculations and modeling conducted is thorough, though it was somewhat difficult to follow all of the calculations, which required flipping to the supplement. The study's findings/calculations have large (honest) error envelops but they show that enhanced weathering could close the projected $P$ gaps of the AR scenario they analyze, decreasing or replacing the use of fertilizers. Further, the authors contend that enhanced weathering has positive impacts on nutrients, soil $\mathrm{pH}$ and soil (micro/macro) nutrient 
pools, while also impacting the plant available water capacity.

Overall I found the manuscript well written (comments below) but I have several structural comments: 1) The combination of "results and discussion" in the second half of the manuscript is very difficult to follow. In particular, I thought this section was pretty much a "discussion and implications" section rather than demonstrating the key findings of this work. l'd ask the authors to consider writing a new concise and clear "results" section clearly outlining what was found with the modeling and calculations, stepping through the calculations, describing the maps in Figures 2 and 3, and the curves int he subsequent figures, as well as the tables. 2) Some important details are buried in the supplement. In particular, I think that portions of S3-S5 sections should be included in more detail in the main text. The manuscript is currently not very long and I think that this would greatly enhance the explanation of what was done in the main text.

I do not think these reorganization suggestions or changes suggested below are very substantial and thus recommend minor revision.

Comments 62: How does this older Gaillardet number compare to those more recently produced by co-author Hartmann's papers and Moon et al. (2014)? I would consider citing all of these sources and giving a range of the $\mathrm{CO} 2$ consumption rate by silicate weathering is.

71-76: Work by Porder and Hilley, as well as Waldbauer and Chamberlain (2005) should be cited in this paragraph or previously.

97: Have others done this type of analysis or suggested this since von Liebig and Playfair (1843)?

108: What about changes in precipitation and runoff? Relatedly, what are the "Parameters" in yellow in Figure 1? It might help to list them on the figure.

169: In addition to Figure 1, a schematic of what is actually being done in the methods

Printer-friendly version

Discussion paper
Interactive

comment

\section{(1)}


would be very helpful. I'm not sure the flow chart fully captures the processes being described in this section.

191: Again, what about changes in runoff to weathering rate? What is this $9 \% / \mathrm{deg} C$ equivalent to in an Arrhenius style calculation? While temperature increases make sense (kinetics) much of the world weathers chemostatically (equilibirium, see Winnick and Maher (2018, EPSL) and papers by Godsey for example) so changes in soil infiltration rate $(\mathrm{P}-\mathrm{ET}=$ runoff $)$ and thus soil moisture should also influence these changes.

220-233: What about the grain size of the rock powder be applied? Does that matter at all? I assume it would be based on reactive transport simulations such as those by Maher $(2010,2011)$ for example. And relatedly how fine the rock is powdered will change the texture described in the next section right?

240-243: Thus, this scenario will be the maximum effect? I think that should be stated explicitly here and elsewhere.

248 (equation 10) and text surrounding: Is this the 'pedotransfer function' mentioned in the above paragraph? Is the only empirical values the lambda? Further, where does the 1930 in the equation come from? A lot of this appears to be buried in the supplement, maybe it'd be more helpful if it is more explicitly stated that this is from Saxton and Rawls (2006) upfront in this section.

332: What about other soil types? Is this information in the literature? What is the most common agricultural soil type?

379: But if they are empirical wouldn't those datasets inherently have clay minerals forming in those systems? In general, I think the caveats brought up in this paragraph should be acknowledged earlier in the paper.

Printer-friendly version

Specific Line by Line Comments 19,21 and 22: Are these ranges 95\%/2 sigma ranges? Lines 147 and 172 suggests that this might be driven by the minimum and maximum harvest rates. What is the central estimate? Abstract should be able to stand on it's 
own so please specify in parentheticals and provide the median or mean estimate.

33 and 34: Please put "i.e." and "e.g." phrases in parentheticals

59: Suggest authors but "i.e., $\mathrm{P}, \mathrm{Mg}, \mathrm{Ca}$ and $\mathrm{K}$ " in the parenthetical before the citation. I also think some more recent work should be cited here and in the next line (60) for controls on atmospheric $\mathrm{CO} 2$ over geologic timescales.

185: Are the databases sources at most 2 by 2 degrees?

196: Suggest putting "cf. Wang et al. (2017)..." as a parenthetical

223: Please add citation and average $P$ content in basalt here.

262: "here estimated" is confusing.

282-283: Is this a citation in the parenthetical?

307: "under study"?

387: please fix grammar of this sentence

442: I would suggest citing Uhlig's papers here rather than what I believe from the reference list list is the PhD thesis. The papers are Uhlig et al. (2017, Biogeosciences) and Uhlig and von Blanckenburg (2019, Frontiers in Earth Science).

Interactive comment on Biogeosciences Discuss., https://doi.org/10.5194/bg-2019-386, 2019. 